\title{
El concepto de colocación a la luz de las colocaciones del tipo verbo más locución adverbial
}

\author{
The concept of collocation in the light of \\ the pattern verb + adverbial idiom
}

INMACULADA PENADÉS MARTÍNEZ

Área de Lingüística General ACEPTADO: 4 DE FEBRERO DE 2017

Departamento de Filología, Comunicación y Documentación

Facultad de Filosofía y Letras

Universidad de Alcalá

Instituto Universitario de Investigación en Lingüística Aplicada

(Univ. de Cádiz)

Colegio San José de Caracciolos

C/Trinidad, 5

28801 Alcalá de Henares-España

inmaculada.penades@uah.es

Resumen: En este trabajo se discuten las características que habitualmente se asignan a las colocaciones: binarismo, pertenencia a la norma y arbitrariedad, y se muestra que estas propiedades no las caracterizan. 1) La relación binaria entre la base y el colocativo queda contradicha por la posibilidad de combinar un mismo colocativo con un conjunto de bases. 2) Asumir que las colocaciones pertenecen a la norma se contradice con la existencia de paradigmas semánticos formados por bases que se combinan con una misma unidad léxica: el colocativo. 3) La propia existencia de los paradigmas semánticos no es un fenómeno arbitrario, sino consecuencia del significado de las unidades que los forman, las bases, uno de cuyos rasgos semánticos forma parte, además, del significado del colocativo. Así se concluye que las colocaciones son estructuras sintagmáticas radiales en las que un rasgo semántico del colocativo determina su combinación con una clase léxica de unidades, las bases, que comparten el mismo rasgo.

Palabras clave: Semántica léxica. Fraseología. Interfaz léxico-sintaxis. Colocación. Locución adverbial. 
Abstract: In this paper we discuss the characteristics that are habitually assigned to collocations: binarism, belonging to the norm and arbitrariness and show that these properties do not in fact define them. 1) The binary relationship between the base and the collocate is contradicted by the possibility of combining the same collocate with a number of bases. 2) The assumption that collocations belong to the norm is refuted by the existence of semantic paradigms formed by bases which combine with the same lexical unit: the collocate. 3) The very existence of semantic paradigms is not an arbitrary phenomenon, but rather, a consequence of the meaning of the units that constitute them, the bases, one of whose semantic features forms part of the meaning of the collocate. Thus, we can conclude that collocations are radial syntagmatic structures in which one semantic feature of the collocate determines its combination with a lexical class of units, bases, which share the same feature.

Keywords: Lexical semantics. Phraseology. Lexical-syntactic interface. Collocation. Adverbial idiom.

\section{INTRODUCCIÓN}

a semántica léxica, al menos desde el enfoque que impulsó el estructuralismo europeo a partir de la segunda mitad del siglo XX (Geckeler 1984a, 246-81), quedó restringida al análisis del significado léxico de los lexemas, en tanto que unidades pertenecientes al sistema de la lengua, sin abordar, por tanto, sus propiedades gramaticales. Con posterioridad, el desarrollo analítico del concepto de interfaz desde el generativismo, y más concretamente el de interfaz léxico-sintaxis, propició el estudio del comportamiento sintáctico de las unidades léxicas, con lo que estas ya no se examinaron solo desde el punto de vista que determina su estructuración en el sistema, sino también desde las posibilidades de combinación que se muestran en el uso lingüístico.

Como es bien sabido, una interfaz es un lugar o zona de encuentro, de contacto o de interacción entre dos sistemas independientes, generalmente de naturaleza distinta (Mendikoetxea 56). Más concretamente, en la concepción generativista de interfaz, el término se refiere a las conexiones de información y comunicación entre los supuestos módulos de la gramática. ${ }^{1}$ En cuanto a la interfaz léxico-sintaxis, de acuerdo con Demonte (19), es prácticamente ya indiscutible que algunas propiedades léxico-semánticas de las palabras explican, en parte, su comportamiento sintáctico; de otro modo, existe un nivel de análisis, la interfaz, donde se expresan y se formalizan las relaciones sistemáticas entre propiedades léxicas y construcciones sintácticas, y viceversa. Con

1. Aunque se ha aplicado también a las conexiones entre la facultad del lenguaje y otros aspectos de la cognición como la visión o el razonamiento, o entre la lingüística y otras ciencias como la filosofía y la psicología (Ramchand y Reiss 2). 
todo, es objeto de discusión el enfoque que se le da a la interfaz léxico-sintaxis; en los enfoques sintácticos los procesos propios de esta interfaz se formulan mediante las categorías y procesos de la sintaxis; por el contrario, en los enfoques léxico-semánticos los procesos de la interfaz se formulan en términos de la semántica léxica (Demonte 22). En Val Álvaro, se presentan las propuestas teóricas que sustentan una y otra perspectiva de la interfaz léxico-sintaxis: la sintactista y la lexicista.

Por otra parte, desde una óptica funcionalista y atendiendo a la primacía de la semántica, también se propugna que la gramática "no puede deshacerse del léxico, ni el léxico puede describirse cabalmente sin recurrir a aspectos gramaticales" (Wotjak 368). En este sentido, no hay que olvidar que, si bien no en el ámbito de la lexicología, sino en el de la sintaxis, el interés por analizar la construcción que se forma al combinar unidades léxicas de la clase verbo con otras de clases distintas, especialmente la de los nombres, fue anterior a la aportación chomskiana. Solo hay que recordar los análisis de la gramática de la valencia (Tesnière) y las investigaciones praguenses sobre la estructura de la oración (Penadés Martínez 1999).

Aunque las cuestiones que atañen al análisis de la interfaz léxico-sintaxis ${ }^{2}$ no se aplican habitualmente a las unidades lingüísticas denominadas colocaciones ni mucho menos se circunscriben a ellas, claro está, no deja de ser cierto que adoptar el punto de vista que conlleva el estudio de las relaciones entre el léxico y la sintaxis debe ser fundamental para abordar las colocaciones, dada su naturaleza pluriverbal, ${ }^{3}$ dicho de otro modo, solo se forma una colocación cuando se combinan al menos dos unidades léxicas (léxico) constituyendo una estructura sintáctica (sintaxis), lo que no significa -casi debe resultar innecesario indicarlo- que toda combinación de unidades léxicas sea una colocación. No es así, como es bien sabido por todos, de ahí la necesidad de precisar las características o las propiedades de las colocaciones, como paso previo al es-

2. Piénsese, por ejemplo, en temas como la interpretación eventiva de los predicados (Escribí el artículo en dos días (evento télico) / Escribi artículos ${ }^{*}{ }^{*}$ en dos días / durante dos días\} (evento atélico) con ejemplos tomados de Demonte), las alternancias verbales (Un trueno rompió el cristal / El cristal se rompio), la polisemia verbal regular (Terry swept / Terry swept the floor / Terry swept the crumbs into the corner / Terry swept the leaves off the sidewalk / Terry swept the floor clean / Terry swept the leaves into a pile), los verbos de comportamiento sintáctico inestable (Gianni ha corso / Gianni è corso a casa) o la variación interlinguística en los patrones sintácticos (esp. subir / bajar / ing. go up / go down), tal como se desprende de Mendikoetxea.

3. Una prueba fehaciente de ello está en el número de trabajos sobre colocaciones incluidos en la obra editada por Veiga, González Pereira y Souto Gómez, la cual, precisamente, se centra en la interrelación léxico-gramática. 
tablecimiento del concepto de colocación. Estos dos puntos (características y concepto), que serán abordados en los apartados 3. y 4. de este trabajo, van precedidos, como no puede ser menos, del análisis de colocaciones concretas (en el apartado 2.) y van seguidos de las conclusiones que se derivan de este estudio (apartado 5.).

\section{ANÁLISIS DE LAS COLOCACIONES COMPLEJAS DEL TIPO VERBO MÁS LO-} CUCIÓN ADVERBIAL

Para el estudio del concepto de colocación se ha partido aquí del análisis de un tipo concreto, el de las colocaciones constituidas por un verbo más una locución adverbial, de manera que ocuparse de la combinación formada por elementos de estas dos clases de unidades lingüísticas implica tratar la dimensión sintagmática no tanto del léxico como de las unidades fraseológicas, lo que no supone obstáculo alguno, ya que un amplio conjunto de locuciones ${ }^{4}$ equivale a unidades léxicas de la clase de los nombres, de los adjetivos, de los verbos o de los adverbios, por lo que pueden abordarse desde los fundamentos teóricos de la semántica léxica, como se comprueba en el análisis semántico de las locuciones nominales, verbales, adjetivas y adverbiales llevado a cabo en Penadés Martínez (2012).

Las colocaciones del tipo verbo más locución adverbial son denominadas en el estudio de Koike (2001, 55-60) colocaciones complejas, término utilizado por este autor ${ }^{5}$ para referirse a la coocurrencia léxica existente entre una locución y una unidad léxica simple cuando entre ambos constituyentes se establece una restricción combinatoria. ${ }^{6} \mathrm{El}$ investigador japonés apunta que la secuencia idiomática, es decir, la locución adverbial, muestra una preferencia léxica y selecciona un determinado tipo de verbo que funciona con significado literal, caso de a mandíbula batiente en relación con el verbo reirse. No obstante, aunque Koike ilustra este tipo de combinación con ejemplos como decir / contar / repetir

4. Por locución se entiende "una combinación fija de palabras que funciona como elemento de la oración y cuyo significado no se corresponde con la suma de los significados de sus componentes" (Penadés Martínez 2012, 23).

5. Véase también Koike (2005), donde amplía el alcance del término colocación compleja al considerar que una unidad léxica se combina con una unidad fraseológica y, asimismo, con otra unidad léxica compleja.

6. La posibilidad de que una colocación esté formada por un colocado que corresponde a una locución ya había sido apuntada por Hausmann. 
/ saber / conocer de pe a $p a{ }^{7}$ no será sino Bosque ${ }^{8}$ quien plantee la hipótesis de que los verbos y los adverbios de manera con los que se combinan, formando una colocación, comparten rasgos semánticos que permiten clasificar los verbos en paradigmas. Y, justamente, para llegar a establecer el concepto de colocación, objetivo último de este trabajo, en este apartado van a ser analizadas locuciones adverbiales con el objetivo primero de probar si su significado léxico o sus particularidades semánticas influyen sobre su combinatoria sintáctica, su sintaxis. La cuestión no es baladí, porque, si los adverbios y las locuciones adverbiales determinan el establecimiento de paradigmas semánticos de verbos, las características de binarismo, pertenencia a la norma y arbitrariedad, más o menos explícitas en determinadas definiciones o caracterizaciones del término colocación, no sirven para diferenciarlo, como se mostrará en 3.

La publicación en 2004 de REDES, el Diccionario combinatorio del español contemporáneo de Bosque (2004a), precedido por otros trabajos como Bosque (2004b), deja patente que ciertos adverbios, especialmente los de manera, y también locuciones adverbiales de esta clase, se constituyen en predicados de eventos representados lingüísticamente por verbos de una misma clase léxica. ${ }^{9}$ No obstante, aunque en este artículo se esté hablando de colocaciones, conviene precisar que, en las obras citadas, el gramático español no utiliza el término colocación, al que renuncia explícitamente (Bosque 2004b, 15), sino el de combinatoria, como prueba el propio subtítulo del diccionario REDES. Esta cuestión queda precisada, en cambio, en el trabajo de Bosque de 2011 y en el de 2017, pues en los mismos títulos se utiliza la denominación colocación. Ahora bien, la datación exacta de la hipótesis planteada por este autor sobre colocaciones constituidas con adverbios de manera, predicados de verbos de una misma clase léxica, importa menos que su demostración, sobre todo en relación con las locuciones adverbiales.

7. Por las mismas fechas García-Page (2001-2002) aporta ya una lista de adverbios, no de locuciones adverbiales, con los verbos y adjetivos con que habitualmente se combinan formando una colocación.

8. Bosque (2004a, 2004b, 2011, 2017).

9. Bosque (2004b) define la noción de CLASE como conjunto de elementos caracterizados por una propiedad. Desde este concepto considera que las clases léxicas contienen información intensional y que no intentan establecer el significado de un lema, pero las clases permiten agrupar conceptualmente los argumentos que corresponden al lema en cuestión. Así, con un ejemplo del mismo autor, los grupos léxicos (clases léxicas) que selecciona el lema de cerca están formados por a) verbos que denotan percepción o captación: ver, captar; b) verbos que denotan vigilancia o control: seguir, vigilar; c) verbos que denotan pertinencia o incumbencia: atañer, incumbir; d) verbos que denotan lanzamiento: disparar, rematar; e) verbos que denotan juicio o examen: examinar, analizar; y f) verbos que denotan relación: relacionar, vincular. 
Por otra parte, ni en los dos primeros estudios de este investigador ni en los dos últimos quedan explícitamente manifiestos los rasgos semánticos compartidos por los predicados adverbiales y sus argumentos externos, los verbos con los que se combinan, dato que justifica la clasificación de los verbos en paradigmas también semánticos. Con lo que se cuenta, que no es poco, es con lo siguiente. El vaciado de las locuciones y las expresiones adverbiales ${ }^{10}$ recogidas en REDES muestra que en 244 entradas, de un total de 579, se delimitan los paradigmas semánticos de los verbos con los que se combinan, ${ }^{11}$ lo que supone un $42,1 \%$, casi la mitad, aunque todavía son muchas las que no los tienen desglosados. ${ }^{12}$ Por ejemplo, a las claras (Bosque 2004a, 172) entra en combinatoria con verbos que designan la acción de expresar o poner de manifiesto algo (decir), con verbos que denotan demostración o comprobación de algo (demostrar) y con verbos de percepción (percibir). ${ }^{13}$

$\mathrm{El}$ autor de REDES advierte que los criterios lingüísticos por los que las locuciones adverbiales en tanto que predicados restringen a sus argumentos deben ser todavía estudiados, entre otras razones porque hace falta investigar la naturaleza de los grupos semánticos constituidos por los argumentos, así como especificar la de los rasgos compartidos entre los argumentos y los predicados con los que se combinan, rasgos que pueden ser aspectuales, semánticos, pragmáticos o discursivos (Bosque 2004a, CXX-CXXI). Y es en

10. El término expresiones adverbiales se utiliza aquí para combinaciones como sin fundamento, sin piedad o sin rumbo, que no son locuciones adverbiales, pero que, sin embargo, tienen entrada en REDES.

11. El vaciado ha sido llevado a cabo por Paula Albert Gandía, becaria de colaboración del Departamento de Filología, Comunicación y Documentación de la Universidad de Alcalá, para el desarrollo del proyecto de investigación La enseñanza de las colocaciones en español lengua extranjera, financiado por el Ministerio de Educación, Cultura y Deporte.

12. Hay que tener en cuenta que el cómputo se ha realizado sin incluir locuciones latinas como $a$ divinis y haciendo caso omiso de las remisiones entre entradas, con lo que a grandes trazos, que remite en REDES a grandes rasgos, se ha contabilizado como una sola unidad. Un recuento que tuviera en cuenta la variación de las locuciones adverbiales modificaría los resultados, pero, muy posiblemente, no se vería alterado en gran modo el porcentaje de las que cuentan con paradigmas de verbos delimitados y las que carecen de la descripción semántica de la clase o clases en que estos se agrupan.

13. Como comprobación adicional a lo apuntado en REDES, téngase en cuenta que la consulta del CREA indica que de las 169 ocurrencias que presenta la locución a las claras en 34 modifica al verbo mostrar, en 19 a demostrar, en 16 a hablar, en 15 a decir, en 13 se combina con indicar, en 8 con dejar y revelar, y en 7 con ver. Las combinaciones con otros verbos no son numéricamente significativas, dado que van de 1 registro, para la mayoría de verbos, a 4 para denunciar y poner. El CREA da cuenta, pues, también de que a las claras se combina con verbos que denotan comprobación o demostración (mostrar (acepción 2), demostrar, indicar, revelar), con verbos de comunicación o que designan la manifestación verbal de algo (hablar, decir) y, en menor grado, con verbos de percepción (ver y también mostrar en su acepción 1). 
este punto donde cobra sentido este trabajo, el cual pretende ser una muestra de las posibilidades que ofrece la investigación de las colocaciones complejas desde la perspectiva planteada por Bosque. Así, entendiendo por sema un rasgo distintivo constituyente de un lexema (Coseriu 1981b, 171), o un rasgo distintivo de contenido mínimo (Geckeler 1984b, 299), y estableciendo los semas de las unidades léxicas o de las fraseológicas a partir de su definición en los diccionarios, ${ }^{14}$ va a examinarse una serie de locuciones adverbiales con la intención de probar que concuerdan con los verbos a los que modifican en algún rasgo semántico.

La locución adverbial a las claras es definida en el DRAE (Real Academia Española 2014, 548, s. v. claro) como 'De manera clara, por la franqueza o por la evidencia' y en el DFDEA de Seco, Andrés y Ramos (286), que registra dos acepciones de ella, como 'De manera clara o sin disimulo' y 'De manera clara o sin duda'. La clave para el análisis de la locución en relación con los verbos con los que se combina la proporciona el elemento 'claro' que conforma las tres definiciones, pues la paráfrasis definitoria de la unidad lingüística correspondiente, el adjetivo claro, en la acepción 7 es 'Que se percibe o se distingue bien' (Real Academia Española 2014, 548), de manera que cabe considerar que [+ perceptible] sería un rasgo semántico de a las claras. Y no solo de esta locución, también del verbo mostrar, el que más ocurrencias presenta combinado con ella a partir de los datos obtenidos del CREA. ${ }^{15}$ En efecto, mostrar en su acepción 1 es 'Manifestar o poner a la vista algo, enseñarlo para que se vea' (Real Academia Española 2014, 1501), en el fondo hacerlo perceptible. Además, desde la acepción 9 de claro en el mismo diccionario, 'Evidente, que no deja lugar a duda o incertidumbre', a las claras también debería definirse a partir de rasgos como [+ evidente] o [+ indudable], rasgos que pueden caracterizar asimismo a demostrar, pues el resultado de 'Probar, sirviéndose de cualquier género de demostración' (acepción 2 de demostrar en Real Academia

14. Esta manera de proceder, tomar la definición lexicográfica de una unidad como correspondiente a su significado, no implica que aquí se identifique definición lexicográfica con significado. Solo la falta de estudios que, con una orientación funcional, proporcionen el significado de las unidades ha conducido a basarse en su definición lexicográfica, pues esta es por ahora el único punto de partida. Sigue siendo cierta la afirmación de algunos autores del Círculo Lingüístico de Praga (Trnka y otros 1967), hecha en 1957, acerca de que, en la lingüística estructural del momento, ningún lingüista había llevado a cabo todavía un análisis estructural completo de una lengua, sobre todo en semántica, excepción hecha de las descripciones logradas en el ámbito de la fonología.

15. La consulta del CREA se ha restringido a España; por otra parte, el periodo de consulta se extiende desde febrero de 2015 hasta junio del mismo año. 
Española 2014, 724) no es otro que convertir en evidente lo demostrado o dejarlo fuera de toda duda. Junto a ello, claro, en su acepción 11 quiere decir para el diccionario de la Academia 'Expresado sin reservas, francamente', y justamente otro conjunto de verbos que se combina con a las claras es el relativo a los verbos que designan la manifestación o expresión de algo (bablar, decir, revelar, explicar, exponer, expresar, entre otros), con lo que locución adverbial y verbos muestran concordancia en un mismo rasgo: [+ expreso]. ${ }^{16}$

En este punto de la exposición, cabe plantearse si la caracterización semántica de a las claras a partir de los rasgos [+ perceptible], [+ evidente] y [+ expreso] implica la existencia de tres significados distintos, con lo que estaríamos ante tres unidades lingüísticas diferentes con una misma expresión fonemática, ya se tratara de polisemia o de homonimia, o, por el contrario, existe un solo signo lingüístico, la locución adverbial a las claras, que actualiza en el uso discursivo uno u otro de los rasgos semánticos anteriores, adquiriendo así el sentido de perceptible, de evidente o de expresado con franqueza según el contexto. La cuestión planteada es central en el ámbito de la semántica y motivo de discusión en función de la teoría lingüística adoptada. Por supuesto, abordarla, no ya resolverla, queda fuera del objeto de estudio de este trabajo.

Con todo, sí conviene precisar que, desde la perspectiva de una semántica funcional (Casas Gómez y Muñoz Núñez 1992, 139-46), es indiferente

16. Los tres significados del adjetivo claro que se han tomado del diccionario académico como base para este análisis: 'Que se percibe o se distingue bien', 'Evidente, que no deja lugar a duda o incertidumbre' y 'Expresado sin reservas, francamente', no entran en contradicción con el análisis que de esta forma adjetiva realiza Maldonado, al contrario, pues el significado base que este autor establece para claro: luminosidad > acceso perceptual sin obstáculos > acceso mental sin obstáculos, está presente, de algún modo, en las distinciones realizadas en la locución a las claras y vinculadas a los distintos paradigmas semánticos de verbos. Así, del significado relativo a lo que se percibe bien por los sentidos ("tu mano derecha mostraba a las claras el escandaloso rojo de la sangre"; "El viejo cofre aparecía completamente vacío, y en su fondo un redondo agujero mostraba a las claras por dónde se había esfumado el preciado polvo dorado") se desprende otro referido a lo que no presenta obstáculos para ser entendido ("El cruce de los datos de difusión de la Prensa por cada mil habitantes con los resultados electorales-dijo-demuestra bien a las claras que el Partido Socialista afianza su voto en aquellas comunidades y provincias donde se difunden escasísimos ejemplares por cada mil habitantes $-25,40$ y $60-$; se trata, por lo tanto, de un voto iletrado"; "haber previamente robado la pócima venenosa, aprovechando la desprevención de su guardiana, y haber atravesado salas, pasillos y escaleras hasta llegar al lugar del crimen demuestra bien a las claras una voluntad delictiva y continuada y un plan previsto de antemano"), y una vez algo ha sido entendido puede ser bien expresado ("dejó de contemplar su manzano y me dijo, si quieres que te lleve a Madrid, dímelo a las claras; a las claras se lo dije, llévame, por Dios, que tanto oxígeno me ahoga"; "fue ella quien le dijo a las claras, un buen día, que lo sabía todo, que le había perdonado y que habría que ir pensando en la fecha de la boda"). 
hablar de polisemia u homonimia, lo que realmente importaría en una unidad calificada de polisémica u homonímica sería comprobar si sus significados pertenecen a un mismo paradigma o campo semántico y, en caso de que así sea, qué tipo de relación semántica existe entre ellos. En la unidad que aquí se toma como referencia, a las claras, cabría establecer campos semánticos distintos para sus tres significados: el de percepción sensorial, el de percepción intelectual y el de expresión o manifestación lingüística, por lo que tendríamos tres signos distintos. En cambio, desde la semántica cognitiva, en a las claras estaríamos ante un caso de polisemia (Ibarretxe-Antuñano; Valenzuela, Ibarretxe-Antuñano y Hilferty 62), dado que podría considerarse que sus significados están motivados o relacionados conceptualmente entre sí. En efecto, el significado de a las claras como 'perceptible' encontraría su razón de ser en la corporeización, en la motivación del lenguaje en nuestra experiencia corpórea, en este caso la derivada de la percepción sensitiva. Por su parte, el significado 'evidente' de a las claras estaría producido por el mecanismo cognitivo de la metáfora, que habría permitido la correspondencia del dominio perceptual sensorial con el dominio perceptual intelectual. Y, tal vez, el significado 'expreso' podría explicarse por el mecanismo conceptual de la metonimia, que permite el acceso de un elemento a otro dentro del mismo dominio: lo que es 'evidente' intelectualmente para el ser humano puede ser expresado, dicho lingüísticamente; la función intelectual y la función lingüística pueden verse como partes del todo que constituye el ser humano.

Otro ejemplo de vínculo semántico entre una locución adverbial y los verbos a los que modifica lo proporciona a bocajarro. Cuando significa 'De manera imprevista', significado para el que en el CREA se cuenta con un total de 43 registros, se combina con los verbos preguntar (24 ocurrencias), soltar (10), espetar (5) o decir (4), los cuales denotan la acción de realizar una manifestación verbal dirigida a alguien. ${ }^{17} \mathrm{El}$ rasgo [+ imprevisto], uno de los que

17. El examen del CREA permite comprobar, asimismo, que a bocajarro, con el significado 'Desde muy cerca' (Seco, Andrés y Ramos, 194), se combina, por una parte, con verbos que denotan disparo con armas o acciones relacionadas con tal hecho: disparar, tirotear, ametrallar, efectuar, realizar, lanzar, recibir, amenazar y asesinar, y, por otra, con verbos vinculados a la acción de lanzar un objeto en el ámbito del deporte, especialmente el del fútbol: fallar, marcar, lanzar, rematar, perdonar y batir. El diccionario de Bosque (2004a, 13-14) no diferencia los dos significados de esta unidad fraseológica, 'De manera imprevista' y 'Desde muy cerca', aunque sí delimita clases léxicas distintas de verbos en combinación con ella: los que denotan disparo, los que denotan alocución o manifestación verbal y los que denotan presencia, muestra o exhibición de algo: presentar, mostrar, aparecer, enfrentar o estrenar, combinación léxica esta última mucho menos frecuente que las dos anteriores. 
definirían la locución, caracterizaría, asimismo, a los verbos soltar y espetar, si se tienen en cuenta las paráfrasis definitorias de sus acepciones 9. y 3., respectivamente, en el diccionario de la Academia: 'Decir con violencia o franqueza algo que se sentía contenido o que debía callarse' y 'Decir a alguien de palabra o por escrito algo, causándole sorpresa o molestia' (Real Academia Española 2014, 2033 y 950), dado que, si se acaba diciendo algo que debía callarse o algo que causa sorpresa, se lleva a cabo una acción imprevista, no tanto una acción realizada de manera impulsiva o impetuosa, que es la caracterización semántica de Bosque (2004a, 14) para la clase léxica que forman estos verbos. Así pues, el rasgo [+ imprevisto] está presente en la locución adverbial a bocajarro y en los verbos soltar y espetar, de modo que se produce una redundancia o una concordancia semántica en las colocaciones complejas constituidas con estas unidades. La locución adverbial significa 'manera imprevista' y este último rasgo está en el significado de estos dos verbos modificados por ella.

Más compleja es la demostración de que la locución a bocajarro comparta tal rasgo semántico con los verbos preguntar y decir; obsérvese que preguntar es el que más ocurrencias tiene en el CREA combinado con a bocajarro, también REDES lo marca como bastante frecuente en esta combinación (Bosque 2004a, 14). En cualquier caso, cabe la posibilidad de considerar que entre la locución adverbial y estos otros dos verbos se da una vinculación de carácter pragmático y no tanto semántico. Si un interlocutor se dirige a otro preguntando o diciendo algo, es posible que el segundo interlocutor no esperara tal manifestación verbal, de manera que cabe inferir que la acción de preguntar y decir le resulta imprevista, uno de los rasgos semánticos propios de a bocajarro. Por otra parte, el que el verbo decir actúe como archilexema de soltar y espetar, definidos ambos como 'decir' más una serie de rasgos específicos, también explicaría la posibilidad de combinarlo con la misma locución adverbial.

Esta propuesta que aquí se presenta no contradice la perspectiva de Bosque, quien en sus trabajos habla de la posibilidad de ampliar un paradigma con unidades que no le pertenecen desde el punto de vista léxico. En razón de la que denomina operación atributiva, ${ }^{18}$ los rasgos que caracterizan un paradigma se predican de nuevos elementos que pueden integrarse en él, dando lugar a

18. Para Bosque (2011, xx), "we may enlarge some paradigms (for example, those of nouns denoting adversity or difficulty) with items which do not belong to them from a lexical point of view (world, truth, life, etc.). This process is an attributive operation, since we predicate the features characterizing the paradigm (for example 'being difficult, adverse, hard, etc' (sic.)) of the new nominal elements that come to be integrated in it". 
paradigmas pragmáticos. Aunque no se trate de una colocación de adverbio o locución adverbial más verbo, sino de una del tipo verbo más sustantivo, lo que se acaba de indicar explica el hecho de que el verbo bordear admita complementos de la clase frontera, orilla, límite, etc., y al mismo tiempo, otros sustantivos que no pertenecen a ese paradigma tan claramente, como cincuentena o jubilación, sustantivos que designan etapas vitales consideradas limítrofes. Para casos como estos, Bosque (2004a, CXXXIII-CXXXIV) señala que es posible ampliar el primer paradigma de sustantivos haciendo encajar en él otros que no son de la misma clase semántica ${ }^{19}$ pero que designan nociones que el hablante interpreta también como limítrofes. En el ejemplo de colocación compleja que estamos examinando, no cabe afirmar que los verbos preguntar, decir, soltar y espetar constituyan dos clases semánticas distintas, una para los dos primeros verbos y otra para los siguientes, pues todos son de la misma clase; no obstante, sí es posible pensar que el concepto 'operación atributiva' propuesto por Bosque sirve para constituir paradigmas pragmáticos, como en bordear la jubilación, y para justificar pragmáticamente paradigmas semánticos, como ocurre con el formado por preguntar, decir, soltar y espetar, en relación con los dos primeros verbos. En consecuencia, los verbos soltar y espetar cuentan per se con el rasgo semántico [+ imprevisto], mientras que a preguntar y decir se les atribuye este rasgo pragmáticamente.

Más todavía, la locución adverbial a bocajarro, junto al rasgo semántico [+ imprevisto], debe contar en su significado, al igual que todas las adverbiales de modo o manera, con el sema genérico [+ manera], o sea, con un clasema, con un rasgo distintivo que funciona en una parte de una categoría verbal (Coseriu 1981b, 175), en este caso la de los adverbios o las locuciones adverbiales que significan modo. ${ }^{20}$ Pero el rasgo en cuestión también podría asignarse a los verbos a los que modifica a bocajarro. En efecto, análogamente a como el tiempo y el espacio se constituyen en un a priori del conocimiento sensible o forman los dos dominios básicos conceptuales más importantes del pensamiento humano, podría afirmarse que la manera o el modo en que los eventos ocurren o se dan, por ejemplo de manera imprevista, es percibido como intrínseco a los propios sucesos, ${ }^{21}$ por lo que, en principio, resulta natural que

19. Bosque (2004b) entiende los términos clase léxica y clase semántica como sinónimos.

20. Se utiliza aquí el término clasema independientemente de toda la problemática que lo rodea. Para una presentación muy ilustradora de la misma, véase Casas Gómez (2001).

21. Pero como Nibil novum sub sole, González García (117) señala que ya J.-P. Golay, en 1959, defendió que los complementos de manera se caracterizan por su carácter interno, inherente 
adverbios de modo o una locución adverbial como a bocajarro modifiquen a verbos como preguntar, decir, soltar y espetar, que por esta razón contarían también con el rasgo clasemático [+ manera]. Se produce, pues, otra justificación pragmática en la vinculación semántica de esta locución adverbial con los verbos examinados.

Además, [+ manera] no sería el único sema genérico de los verbos anteriores, pues también [+ acción], [+ humano] y [+ transitividad] deberían formar parte de la descripción de los respectivos lexemas, de modo que, ya se aplique el término clasema a un solo sema, ya designe un conjunto de semas genéricos ([+ acción], [+ humano], [+ transitividad], [+ manera] en los verbos preguntar, decir, soltar y espetar), estamos ante rasgos semánticos generales que funcionan como marca de combinatoria sintagmática, pues explican el hecho de que estos verbos se construyan con un sujeto humano agente, con un objeto directo y con un adverbio o una locución adverbial de manera, aunque en este caso como elemento adjunto, no argumental, frente al sujeto y el objeto directo.

En otros casos, las conexiones que un hablante nativo establece entre los elementos de una combinación léxica corresponden a extensiones figuradas, metafóricas, que el diccionario de Bosque (Bosque 2004a, CXV; Bosque 2004b, 45) no pretende explicar porque intervienen factores históricos y culturales de gran complejidad, lo que no nos impide acercarnos a estas cuestiones desde la perspectiva que ofrece la lingüística cognitiva (Penadés Martínez 2011). Así, por ejemplo, a gloria y sobre ruedas, que no tienen asignadas clases léxicas de verbos en REDES (Bosque 2004a, 1682), ${ }^{22}$ podrían analizarse del siguiente modo. Estas locuciones, aun significando ambas 'Muy bien', forman colocaciones complejas con verbos de clases semánticas distintas. A partir de las muestras que ofrece el CREA, a gloria se combina con saber, sonar, oler y retumbar, paradigma de los verbos de percepción sensitiva, y sobre ruedas, con $i r$, marchar, discurrir, deslizarse y seguir, todos ellos verbos, en principio, de movimiento, pero usados en la acepción relativa a denotar que algo funciona o

al proceso. De manera análoga, Dik, a partir de 1975, ya argumentaba que los constituyentes que especifican el modo de algún estado de cosas pueden aparecer en cualquier tipo de estados de cosas, excepto los no controlados y los no dinámicos, es decir, los estados. Lo cual significa que pueden existir constituyentes de modo con acciones, posiciones y procesos, de manera que, en una predicación nuclear que designe cualquiera de estos estados de cosas, el modo está implicado inmediatamente, o sea, se comprende que la acción, la posición o el proceso se llevan a cabo o tienen lugar de algún modo (Dik 76).

22. La primera locución, a gloria, no está recogida en Bosque (2004a). 
se desarrolla. Tal como se ha indicado anteriormente, podría afirmarse que el modo o la manera en que los eventos ocurren o se dan: bien, mal, regular, etc., son percibidos como intrínsecos a los propios sucesos, por lo que, en principio, resulta natural que adverbios de modo como bien, muy bien, mal, muy mal, y locuciones adverbiales con los significados de estos adverbios, modifiquen a los verbos. La explicación específica de por qué sobre ruedas se combina con $i r$, marchar, discurrir, deslizarse y seguir tiene que ver ya con el proceso metafórico que permite proyectar el dominio concreto del movimiento real sobre el dominio abstracto del desarrollo de algo, con lo que se crea la metáfora LA MARCHA DE UN ASUNTO ES LA MARCHA DE UN AUTOMÓVIL. ${ }^{23}$ De manera inversa, en el caso de saber u oler a gloria, la situación abstracta de bienaventuranza, incluso de felicidad, que se obtendría estando en el cielo, en el Paraíso, en la gloria, contemplando a Dios, se proyecta sobre el fenómeno sensorial, concreto por tanto, de degustar u oler un alimento muy sabroso, o de percibir un sonido muy agradable: sonar o retumbar a gloria, así que ahora se da lugar a la metáfora UNA PERCEPCIÓN SENSORIAL BUENA ES LA GLORIA CELESTIAL.

\section{CARACTERÍSTICAS DE LAS COLOCACIONES}

Pero si las locuciones adverbiales de manera determinan el establecimiento de paradigmas semánticos de verbos, las propiedades de binarismo, pertenencia a la norma y arbitrariedad, presentes, de manera más o menos explícita, en determinadas definiciones o caracterizaciones del término colocación, ${ }^{24}$ no sirven para diferenciarlo, tal como ya apunta Bosque (2011) en relación con la primera, el binarismo, y la última, la arbitrariedad. No son pocos los autores que en su caracterización de las colocaciones inciden en vincular el concepto de colocación a la preferencia de dos palabras por colocarse: una, el colocativo, con la otra, la base, de manera que dan lugar a una relación binaria exclusiva. Las combinaciones de una locución adverbial, o un adverbio, con un conjunto más o menos extenso de verbos contradice esta concepción binaria, y ello aunque para algunas colocaciones complejas solo exista un verbo seleccionado por la locución adverbial, como reir en relación con a mandibula batiente o llorar respecto a la locución

23. Para explicar la formación de sobre ruedas es necesario acudir también al proceso metonímico de PARTE POR TODO.

24. Alonso Ramos (1994-1995, 2000, 2017); Blasco Mateo; Corpas Pastor (1996, 66; 1998, 2001, 2017); García-Page (2001-2002); Muñiz Álvarez; Zuluaga. 
a lágrima viva. ${ }^{25}$ Que estas colocaciones concretas, y otras más, muestren la característica del binarismo no es obstáculo para considerar que esta propiedad no caracteriza a las colocaciones, puesto que ya es vieja la idea de que no todos los rasgos de una clase se dan en todos los elementos de la clase, como bien explica la distinción praguense entre centro y periferia (Daneš). Por otra parte, el hecho de que distintas locuciones adverbiales se combinen con diferentes paradigmas semánticos de verbos se constituye en un procedimiento para fijar los límites de campos semánticos, uno de los problemas en el estudio estructural de las unidades léxicas, pues no siempre se ha dispuesto de criterios para el establecimiento de campos semánticos (Penadés Martínez 1994). Además, y de rechazo, el no binarismo de las colocaciones complejas confirma la validez de los presupuestos teóricos, de corte claramente funcional, que mantienen que a una misma combinatoria sintagmática le corresponde una homogeneidad semántica o, en palabras de la semántica estructural, un contenido léxico continuo.

En cuanto a la característica que vincula las colocaciones al plano de la norma y del uso, asumirla implica excluirlas del sistema lingüístico, lo que contradice las posibilidades que el propio uso demuestra, pues, como ha podido comprobarse, la existencia de paradigmas semánticos con una misma combinatoria léxica es un hecho sistemático que debe ser establecido de manera particular para cada lengua, es decir, para cada sistema lingüístico, ya que, como es de sobra conocido, no siempre son coincidentes las combinaciones de una lengua en relación con las de otra. La combinatoria de locuciones adverbiales con clases de verbos da lugar, además, a estructuras sintagmáticas radiales, en el sentido de que desde una locución adverbial, vista como un centro, arrancan los radios que conducen a los verbos de la clase semántica en cuestión, tal como ilustra la siguiente figura:

25. La consulta del CREA muestra 20 ocurrencias de a mandíbula batiente, 18 con el verbo reír, y 2 con llorar y reventar; la primera puede tratarse de un error del hablante, llorar a mandíbula batiente en vez de a lágrima viva: "Mientras la ciudad de Palma se echaba a la calle, el vestuario del Rayo lloraba. Y lo bacía a mandibula batiente"; la segunda puede corresponder a una asociación entre reír a mandibula batiente y reventar de risa, más la elipsis de de risa: "- No se puede parar - dijo la "Nena" haciendo un esfuerzo por contener las carcajadas [... La "Nena" y la anciana reventaron a mandíbula batiente". Por su parte, de a lágrima viva aparecen 22 registros en el CREA, todos con llorar, excepto también 2 construidos con reconocer y lacrimear: "Sabine Leutheusser reconocía a lágrima viva que en su partido se había operado un "cambio de rumbo" importante en cuanto a política de Interior y Justicia", ejemplo difícilmente explicable, y "Julián lacrimeaba a lágrima viva cuando llegó a casa. Es imposible saber ya si lacrimeaba o lloraba. Hubiera podido ser cualquiera de las dos cosas. Ambas crónicas, al fin y al cabo, la conjuntivitis y el desconsuelo", ejemplo del que hay que indicar que lacrimear no es recogido por el DRAE, pero en el texto aparece coordinado con llorar. 


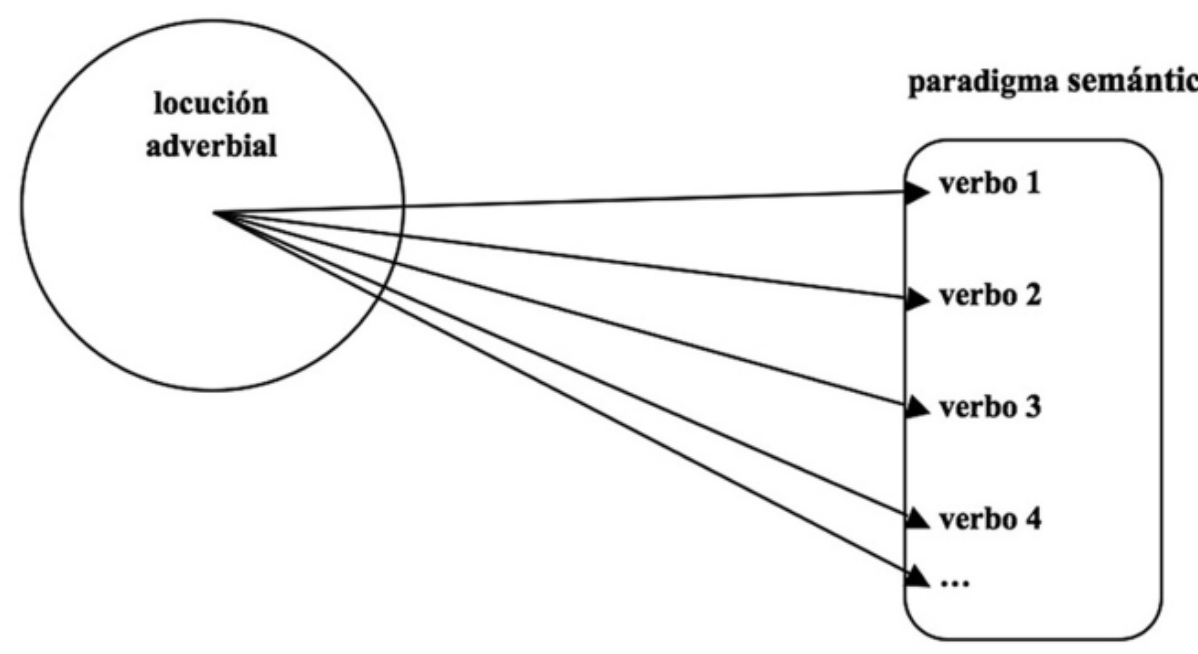

Habría que buscar, en consecuencia, el estatus teórico de este tipo de estructura no delimitado por la semántica estructural clásica, a pesar de que algunos autores ${ }^{26}$ hayan establecido vinculaciones entre las colocaciones y las solidaridades léxicas de Coseriu (1981a). Pero es que, además, las estructuras radiales pueden vincularse en forma de red, con lo que las relaciones entre unidades se incrementan:

26. Corpas Pastor (1996, 63-65; 2015); García-Page (1990, 2005); Ginebra; Koike (2001, 18); Muñoz Núñez. En algún caso no se trata de vinculación sino de identificación, es decir, las colocaciones (modificar sustancialmente, negar tajantemente) son identificadas con las solidaridades léxicas (Thielemann 1996, 62-63). 


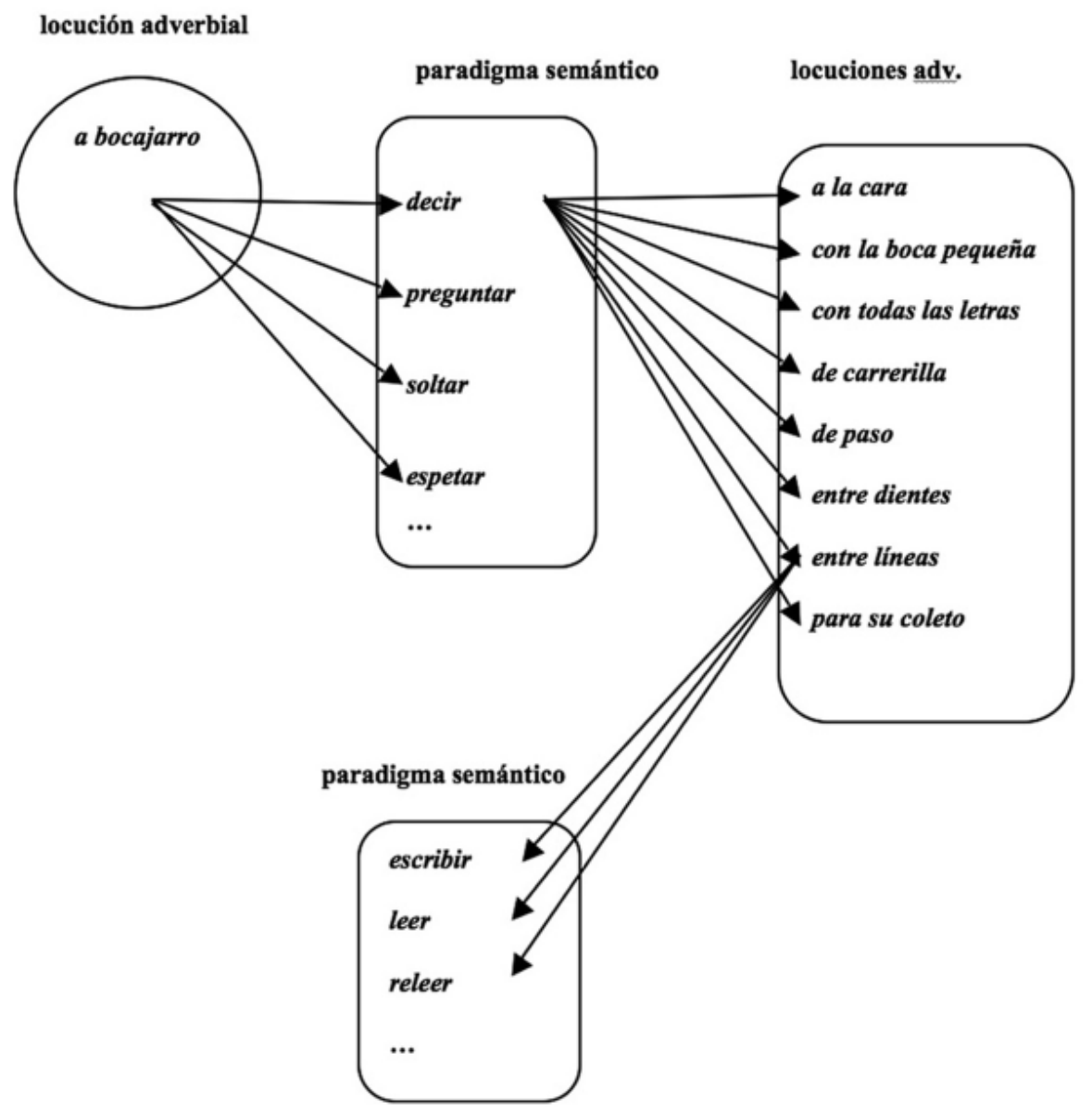

Por lo que respecta a la característica de la arbitrariedad, el hecho de que un conjunto de unidades léxicas específicas pertenezca a una clase semántica conduce a Bosque (2011, XXI) a afirmar que la mayoría de colocaciones no son arbitrarias, pues la existencia de la propia clase semántica no es un fenómeno arbitrario, sino consecuencia del significado de las unidades que la forman; esto por lo que se refiere a las bases de las colocaciones. En cuanto a los colocativos, al no ser componentes opacos de combinaciones binarias memorizadas individualmente, sino predicados restringidos por estructuras sintácticas motivadas, tampoco se puede hablar de la existencia de arbitrarie- 
dad en relación con ellos. ${ }^{27}$ Cuestión distinta es que todavía deba ser determinado el grado en el que las colocaciones son unidades motivadas, deducibles y composicionales (Bosque 2017). La propuesta de este autor es, no obstante, matizada por Alonso Ramos (2017), quien considera que, desde la perspectiva del análisis específico de las colocaciones, las bases (los verbos en las colocaciones complejas que aquí se analizan), efectivamente, se pueden organizar en grupos; sin embargo, desde la perspectiva del hablante que produce una colocación, estas unidades son combinaciones binarias, pues el emisor parte de una unidad léxica única y no de un grupo de unidades léxicas, de manera que no es posible distinguir entre colocativos (locuciones adverbiales en nuestro caso) combinados con un grupo de bases y colocativos combinados con una base. Ahora bien, la objeción de Ramos Alonso surge de una perspectiva epistemológica no del todo legítima, pues, si bien es verdad que el investigador, el lingüista, debe explicar la producción lingüística del hablante, la explicación científica no puede hacerse corresponder con la actuación del hablante, sino con el comportamiento de las propias unidades lingüísticas objeto de análisis, el cual demuestra que las colocaciones son deducibles justamente por los rasgos semánticos en los que se corresponden colocativos y bases. Son planos distintos los que atañen al estudioso de la lengua y al hablante. Otra cosa es, claro está, que la tarea del lingüista, en cuanto lexicógrafo por ejemplo, tenga por objetivo ayudar al hablante en la producción de colocaciones, de ahí el interés en elaborar diccionarios que las registren.

Por el contrario, Bosque (2011, VII-VIII) sí acepta que las colocaciones son arbitrarias en el sentido saussureano del término, de este modo, aplicando las ideas del maestro ginebrino a estas unidades lingüísticas (Saussure 130-33), el significante de una colocación no guardaría en la realidad ningún lazo natural con su significado y tampoco habría relación, parecido o vínculo entre el significante y el significado de una colocación. No obstante, las explicaciones cognitivas de a gloria y sobre ruedas muestran a las claras la motivación de tipo semántico ${ }^{28}$ en la restricción que tales locuciones adverbiales imponen a sus respectivos argumentos, de manera que muchas colocaciones complejas tampoco son arbitrarias en el sentido en que Saussure explicó la arbitrariedad de los signos lingüísticos. La existencia de motivación en las

27. Desde otra perspectiva, la de la enseñanza del inglés como lengua extranjera, en Walker se defiende la idea de que los procesos colocacionales no son arbitrarios, sino motivados.

28. Para una caracterización de la motivación semántica dentro de los distintos tipos de motivación, ver Penadés Martínez y Díaz Hormigo (2008). 
colocaciones las asemeja a las unidades léxicas, clase en la que existen tanto signos lingüísticos arbitrarios como signos motivados fonética, morfológica y semánticamente.

Pero, además, en algunas ocasiones, son datos de naturaleza diacrónica los que dan cuenta de que la relación entre la base y el colocativo de una colocación no es arbitraria, sino motivada. Ocurre esto con el predicado perdidamente y el argumento externo enamorado al que modifica. En efecto, el equivalente de traducción del español perdición al latín es perniciēs, con el significado de 'destrucción física, ruina, muerte' (Ernout y Meillet 440; Glare 1348), palabra derivada, a su vez, de per más nex, 'muerte' (Ernout y Meillet 439; Glare 1175), de manera que cobra sentido etimológico la predicación de perdidamente en relación con enamorado, si se piensa, además, en la vinculación de la pasión amorosa con la enfermedad (Jiménez Calvente) e incluso con la muerte. Asimismo, la relación del amor con la locura, ya percibida en el mundo clásico (Jiménez Calvente), explica la colocación locamente enamorado, en la que el adverbio de modo ha pasado a indicar el alto grado en que se está enamorado; el DUE (Moliner 291) lo define como 'Mucho o muy' y se refiere a locamente enamorado como expresión muy frecuente; por su parte, el DRAE (Real Academia Española 2014, 1355) registra para locamente una segunda acepción definida como 'Excesivamente, sin prudencia ni moderación'; por último, desde la Teoría del Sentido-texto, al adverbio de esta colocación le correspondería la función léxica o el sentido de Magn (Alonso Ramos 19941995). De manera análoga, también es motivada la colocación comer opíparamente o comida opípara, en este caso por la relación etimológica con el latín ops, opis, 'abundancia, recursos, riquezas' (Ernout y Meillet 463); de ahí la explicación de que una comida opípara se refiera a espléndida y copiosa (Real Academia Española 2014, 1579), cualidades que, a través del proceso metonímico EFECTO POR CAUSA, son proporcionadas por la riqueza o la abundancia de recursos. Hay que tener en cuenta, asimismo, que opiparus, con el significado de 'abundante en recursos, ricamente preparado, abundante' (Ernout y Meillet 464), es ya en latín un derivado de ops. ${ }^{29}$

29. Agradezco a la profesora Teresa Jiménez Calvente, titular de Filología latina y compañera de la Universidad de Alcalá, que me haya facilitado la información etimológica que permite analizar estas colocaciones como motivadas desde una perspectiva diacrónica, aunque no sean sentidas así por el hablante no especialista en el estudio de la lengua. 


\section{EL CONCEPTO DE COLOCACIÓN}

Para llegar al concepto de colocación desde lo expuesto hasta ahora hay que tener en cuenta dos cuestiones: primera, que debe basarse en las propiedades que manifiesta el estudio de colocaciones concretas y, segunda, que la semántica léxica estructural ofrece los fundamentos teóricos para establecerlo. El análisis de las colocaciones complejas y lo desarrollado en el apartado anterior ha mostrado que binarismo, pertenencia a la norma y arbitrariedad no son propiedades que las caractericen. Como se ha observado a lo largo de este trabajo, la relación entre los elementos de una colocación compleja no es binaria: de uno a uno, sino de uno a varios; por otra parte, el que esta relación esté condicionada por la existencia de rasgos semánticos determina su carácter sistemático, no perteneciente a la norma; además, la motivación que en ciertos casos preside la relación entre una base y un colocativo equipara las colocaciones a las unidades léxicas del sistema de la lengua, donde existen tanto signos motivados como arbitrarios.

Dadas estas condiciones, cabe partir del concepto de solidaridad léxica, tal como es concebido por la lexemática coseriana, para explicar las unidades que aquí son objeto de estudio. Para este autor (Coseriu 1981b, 182) las solidaridades léxicas son estructuras sintagmáticas motivadas por su valor de lengua. Por su parte, según el análisis realizado, las colocaciones complejas, y también las colocaciones de dos unidades léxicas, son estructuras sintagmáticas radiales en las que un rasgo semántico del colocativo determina su combinación con una clase léxica de unidades, las bases, que comparten el mismo rasgo. El hecho de que una colocación sea una estructura sintagmática implica, además, que entre sus elementos, ya sean todos unidades léxicas ya sean unidades léxicas y fraseológicas, se establecen relaciones sintácticas propias de un grupo nominal, de un grupo adjetival o de un grupo verbal. $\mathrm{Y}$ esta particularidad permite diferenciar una colocación de otras unidades lingüísticas con las que suele relacionarse: las locuciones y los compuestos sintagmáticos.

Efectivamente, en la colocación del tipo un fumador empedernido existe la misma relación de determinación entre determinante y sustantivo, y de modificación del sustantivo por parte del adjetivo, que en el grupo nominal un director responsable. Entre el colocativo extremadamente y la base débil se establece la relación sintáctica de modificador - modificado, propia de grupos adjetivales como demasiado cansado. Por su parte, rotundamente es, asimismo, el colocativo 
que modifica al verbo base afirmar constituyendo un grupo verbal análogo al que se forma con un adverbio y un verbo que no forman colocación: escribir despacio. Además, colocaciones formadas por un sustantivo objeto como base (delito) y un verbo como colocativo (cometer), insertadas en el discurso, manifiestan estructuras actanciales ${ }^{30}$ semejantes a las existentes en muchos enunciados con grupos verbales que no corresponden a colocaciones verbales. ${ }^{31}$

Sin embargo, en las locuciones tales relaciones sintácticas no existen, dado que el establecerlas implicaría destruir el todo unitario que constituye una locución (Penadés Martínez 2014). Efectivamente, ¿qué determinación y qué modificación aportan el y del loro a chocolate, pensando que la unidad el chocolate del loro significa 'Cosa, especialmente cantidad de dinero, insignificante en comparación con otra'?; ¿qué modificación, asimismo, conlleva el sintagma preposicional de cascos respecto al adjetivo ligero en la locución adjetiva ligero de cascos?; por último, caerse el pelo es una combinación fija de palabras, en concreto una locución verbal, que, de manera conjunta, funciona en una oración como lo haría un verbo y en ella no es posible establecer un análisis que conduzca a considerar que el pelo es un actante en función de sujeto, pues, de proceder así, sería imposible diferenciar entre la locución de "El fotógrafo tiene que llevarle la foto al redactor jefe. Si no se la lleva se le cae el pelo. El redactor jefe no acepta esas excusas", y la combinación libre de palabras, no fraseológica, de "Llevaba semanas sin afeitar y se le había caído el pelo en forma irregular dejando al descubierto aquí y allá franjas de cuero cabelludo", donde el pelo sí es sujeto de se había caído.

Tampoco los compuestos sintagmáticos se pueden analizar desde esta perspectiva sintáctico-funcional, pues precisamente uno de los criterios para distinguirlos (Díaz Hormigo 77-81), frente a los sintagmas libres, es el presentar un comportamiento unitario, de manera que resulta imposible separar los elementos constitutivos del compuesto sintagmático intercalando complementos modificadores ( ${ }^{*}$ bora sumamente punta), o incluir el artículo delante del segundo elemento integrante de la formación compuesta (*agencia de los viajes), o adjuntar términos adyacentes para cada componente, pues su admi-

30. Así, al enunciado "opinó que decisiones como la del juez de Sant Feliu sirven para "criminalizar a los padres", a quienes no se les puede imputar un delito" le corresponde una estructura actancial constituida por un sujeto agente (aunque el enunciado anterior corresponda a una oración impersonal), un objeto directo tema (un delito) y un objeto indirecto afectado ( $a$ quienes): alguien imputa algo a alguien.

31. La misma estructura actancial anterior subyace al enunciado "Alvarina Odalisca le leía los poemas de Eliseo a su hermana Elsa": alguien lee algo a alguien. 
sión indica que no hay compuesto (Tenía unos ojos preciosos de gato, Tenía unos ojos de gato salvaje, Un OfO DE GATO muy valioso)..$^{32}$

En síntesis, cabe, pues, afirmar que las colocaciones son estructuras sintagmáticas radiales, sistemáticas y semánticamente deducibles, además de la posible motivación semántica o diacrónica de algunas de ellas.

\section{CONCLUSIONES}

De todo lo expuesto se deduce una serie de conclusiones que paso a desglosar.

1. Es necesario seguir analizando amplios conjuntos de colocaciones complejas de verbo más locución adverbial, o de otro tipo, con el objetivo de determinar el rasgo o los rasgos que colocativo y base comparten, y las clases léxicas a las que las bases dan lugar, de ese modo quedará claramente probado que las colocaciones no son unidades binarias, no pertenecen a la norma y no son arbitrarias.

2. La imposibilidad de asignar las propiedades anteriores a las colocaciones invalida las definiciones de colocación con que habitualmente venimos trabajando, por lo que sería necesaria una nueva caracterización de este término, la cual, por supuesto, no puede realizarse via negationis, a partir de la indicación de lo que no son las unidades que recubre, por su palmaria insuficiencia.

3. Al vincular las colocaciones con las solidaridades léxicas delimitadas por Coseriu, tal como hasta el momento se ha hecho, parece haberse obviado que para el profesor de Tubinga (Coseriu 1981b, 169) estas son estructuras lexemáticas. Partiendo, pues, de que las solidaridades son estructuras sintagmáticas ${ }^{33}$ motivadas por su valor de lengua (Coseriu 1981b, 182), sería posible considerar las colocaciones estructuras sintagmáticas radiales, tal como ha quedado demostrado anteriormente, de manera que esta caracterización puede ser el punto de partida para su definición y para su delimitación frente a otras unidades lingüísticas con las que las colocaciones suelen relacionarse: las locuciones y los compuestos sintagmáticos, que, de ningún modo, pueden analizarse como una estructura formada por unidades con funciones sintácticas propias. Incluso sería posible empezar a pensar en unas relaciones semán-

32. Los ejemplos de este párrafo están tomados de Díaz Hormigo (77).

33. El que sean sintagmáticas y no paradigmáticas es una cuestión que aquí no tiene incidencia. 
ticas sintáctico-paradigmáticas, pues no en vano las colocaciones se enmarcan en la interfaz que forman el léxico y la sintaxis.

4. El análisis semántico realizado de las colocaciones complejas prueba, de manera adicional, que el clasema es un rasgo de valencia combinatoria, tal como ya se ha apuntado (Casas Gómez 2001, 288), y que las posibilidades de combinación de los lexemas forman parte de su significado configurando el contenido léxico junto con rasgos de carácter paradigmático. Queda explicada la dimensión sintagmática de la lengua y rechazada la identificación de lo sintagmático con el habla, dado el reduccionismo de lo semántico, en gran parte de la lingüística estructural, al ámbito exclusivamente paradigmático, y ello desde una perspectiva que desarrolla e ilustra la subrayada por Casas Gómez (2001). ${ }^{34}$

5. El estudio descriptivo llevado a cabo sobre las colocaciones complejas formadas por un verbo más una locución adverbial, realizado desde una perspectiva sincrónica, ha mostrado que no es posible obviar el punto de vista diacrónico, de manera que se produce una integración de estos dos modos de enfocar el análisis de la lengua. También se ha percibido que la descripción de las colocaciones no puede hacerse ignorando los desarrollos de teorías lingüísticas plenamente actuales, como es el caso de la lingüística cognitiva, cuyas aportaciones sobre los fenómenos conceptuales de la metáfora y de la metonimia habrá que explorar, en relación con el español, para la interpretación más pragmática que semántica de algunos rasgos y para explicar aquellas colocaciones en que es más patente el significado idiomático. Las formadas por una unidad léxica y una locución son firmes candidatas a ser de este tipo, simple y llanamente por la idiomaticidad que caracteriza a las locuciones.

6. Considerando, pues, que las colocaciones son estructuras sintagmáticas radiales y que entre los elementos que las constituyen se establece algún tipo de relación por su respectiva función sintáctica, las colocaciones no deben ser unidades objeto de estudio de la fraseología porque no participan de las características de las unidades fraseológicas: fijación formal, fijación estructural (Penadés Martínez 2014) y fijación semántica. La afirmación implica mantener una concepción estrecha de la fraseología, frente a la concepción amplia

34. En Casas Gómez (2015) también se insiste en la necesidad de contemplar desde la semántica la dimensión sintagmática de la lengua. Por otra parte, de Hummel se deriva que el sintagmatismo de la lengua pertenece al significado lingüístico, dicho de otro modo, que los signos cuentan con un significado gramatical, con unos rasgos abstractos de las funciones contextuales que pueden atribuirse a un signo lingüístico. 
sustentada por algunos autores (Corpas Pastor 1966) y frente a la caracterización de las colocaciones como unidades semi-fraseológicas (Alonso Ramos 2002). ${ }^{35}$ Pero si las colocaciones no se sitúan en la fraseología, el ámbito que les es propio tampoco puede ser la lexicología ni la semántica de manera exclusiva, sino, justamente, la interfaz léxico-sintaxis, como nueva perspectiva de la semántica léxica.

7. Las colocaciones complejas presentan implicaciones teóricas y aplicadas para otras cuestiones que aquí no se han desarrollado, sin embargo no quisiera dejar de apuntarlas. En cuanto a las primeras, tienen que ver con el problema de la sinonimia. Si locuciones adverbiales con el mismo significado, como las que quieren decir 'Muy bien', forman colocaciones complejas con verbos de clases semánticas distintas, la sinonimia se vincula a la distribución complementaria (Penadés Martínez 2012). La afirmación surge de casos como la combinación de a gloria con saber, sonar, oler y retumbar, y la de sobre ruedas con ir, marchar, discurrir, deslizarse y seguir.

Por su parte, las implicaciones aplicadas atañen a los ámbitos de la lexicografía y de la enseñanza de la lengua como L2. En cuanto al primero, conviene subrayar aquí que, con excepción hecha de los diccionarios REDES y Práctico (Bosque 2004a, 2006), no es habitual encontrar obras lexicográficas que proporcionen la combinatoria de una unidad, y menos aún si se trata de diccionarios semasiológicos. De ahí la conveniencia de aplicar los estudios sobre las colocaciones con los que se cuenta y los que se puedan desarrollar en el futuro a la redacción de diccionarios, favoreciendo una imbricación de diccionarios de combinatoria léxica y semasiológicos.

En cuanto a la implicación aplicada relativa a la enseñanza de la L2, cabe destacar que el establecimiento de los paradigmas semánticos de verbos que pueden ser modificados por determinadas locuciones adverbiales constituye un apoyo mnemotécnico para el aprendiz de la lengua, que no se ve obligado a memorizar pares de unidades lingüísticas que van juntas aparentemente sin justificación alguna. ${ }^{36}$ Lo expuesto en este trabajo permite hacerle ver al alumno la relación semántica entre los elementos de una clase léxica, los ver-

35. El uso del prefijo semi- conduce a considerar que son unidades fraseológicas a medias, lo son en parte sí y en parte no.

36. Una prueba de lo afirmado la constituye la investigación de Albert Gandía, quien, a partir de los fundamentos teóricos desarrollados aquí, ofrece una propuesta didáctica para la enseñanza de las colocaciones formadas, precisamente, por un verbo más una locución adverbial. La propuesta en cuestión está recogida en Abad Asín y Albert Gandía. 
bos, y la sintáctico-semántica entre ellos y otra unidad lingüística, la locución adverbial.

Como conclusión general, solo queda añadir que la semántica léxica estructural puede constituirse en fundamento teórico para el análisis de las colocaciones, tanto por los conceptos de rasgo distintivo y clasema, como por los de estructura sintagmática y solidaridad léxica. De este modo, si bien en la semántica estructural clásica no se llegó a plantear la posibilidad de una estructura sintagmática radial ni de unas relaciones semánticas sintáctico-paradigmáticas, sí es posible afirmar que estos dos últimos conceptos constituyen un punto de partida que la semántica léxica actual, como se indica en la introducción de este volumen, deberá explotar y desarrollar en el análisis de la combinatoria léxica, es decir, en la investigación sobre la interfaz léxico-sintaxis.

\section{OBRAS CITADAS}

Abad Asín, Carlota, y Paula Albert Gandía. Combina palabras y formula ideas. Alcalá de Henares: Servicio de Publicaciones de la Universidad de Alcalá, 2016.

Albert Gandía, Paula. Las colocaciones complejas en el aula de ELE. Nueva propuesta didáctica. Trabajo fin de máster inédito. Universidad de Alcalá, 2015.

Alonso Ramos, Margarita. "Hacia una definición del concepto de colocación: de J. R. Firth a I. A. Mel'čuk". Revista de Lexicografía I (1994-1995): 9-28.

Alonso Ramos, Margarita. "Colocaciones y contorno de la definición lexicográfica”. Lingüística Española Actual XXIV/1 (2002): 63-96.

Alonso Ramos, Margarita. "Can collocations be deduced? A lexically-driven analysis from the perspective of language production". Collocations and other lexical combinations in Spanish. Theoretical and applied approaches. Eds. Sergi Torner y Elisenda Bernal. London: Routledge. 2017. 21-40.

Blasco Mateo, Esther. "La lexicalización y las colocaciones". Linguïstica Espanola Actual XXIV/1 (2002): 35-61.

Bosque, Ignacio, dir. Las palabras en su contexto. REDES. Diccionario combinatorio del español contemporáneo. Madrid: Ediciones SM, 2004a.

Bosque, Ignacio. "La dirección en los diccionarios combinatorios y el problema de la selección léxica". Lingüística Teòrica: anàlisi i perspectives. I. Catalan Fournal of Linguistics Monographies. Ed. Teresa Cabré, 2004b. 13-58. 8 de diciembre de 2015. <http://filcat.uab.es/clt/publicacions/ coleccions/monografies/pdf/LT-I-Bosque.pdf>. 
Bosque, Ignacio, dir. Diccionario combinatorio práctico del español contemporáneo. Las palabras en su contexto. Madrid: Ediciones SM, 2006.

Bosque, Ignacio. "Deducing collocations". Proceedings of the $5^{\text {th }}$ International Conference on the Meaning-Text Theory. (Barcelona, September 8-9, 2011). Eds. Igor Boguslavsky y Leo Wanner. Barcelona, 2011. VI-XXIII. 22 de diciembre de 2015. <http://olst.ling.umontreal.ca/pdf/proceedingsMTT2011.pdf>.

Bosque, Igancio. "On the conceptual bases of collocations: restricted adverbs and lexical selection". Collocations and other lexical combinations in Spanish. Theoretical and applied approaches. Eds. Sergi Torner y Elisenda Bernal. London: Routledge. 2017. 9-20.

Casas Gómez, Miguel. "Origen y desarrollo del concepto de "clasema"”. Actas del II Congreso Internacional de la Sociedad Española de Historiografía Linguiística. (León, 2-5 de marzo de 1999). Eds. Marina Maqueira Rodríguez, $M^{a}$ Dolores Martínez Gavilán y Milka Villayandre Llamazares. Madrid: Arco/Libros, 2001. 277-91.

Casas Gómez, Miguel. "Propuesta para una clasificación de las relaciones en semántica”. V Fornadas de Lengua y Comunicación. Léxico: enseñanza e investigación. Coords. Manuel Martí Sánchez e Inmaculada Penadés Martínez. Linguística en la Red XIII (2015): 1-22. 28 de diciembre de 2015. $<$ http://www.linred.es>.

Casas Gómez, Miguel y M. Dolores Muñoz Núñez. "La polisemia y la homonimia en el marco de las relaciones léxicas”. Estudios de lexicología y metalexicografía del español actual. Ed. Gerd Wotjak. Tübingen: Max Niemeyer, 1992. 134-58.

Corpas Pastor, Gloria. Manual de fraseología española. Madrid: Gredos, 1996.

Corpas Pastor, Gloria. "Expresións fraseolóxicas e colocacións: clasificación". Actas do I Coloquio Galego de Fraseoloxía. (Centro Ramón Piñeiro, Santiago de Compostela, 1997). Coord. Xesús Ferro Ruibal. Vigo: Xunta de Galicia, 1998. 31-61.

Corpas Pastor, Gloria. “Apuntes para el estudio de la colocación”. Lingiuística Española Actual XXIII/1 (2001): 41-56.

Corpas Pastor, Gloria. "Register-specific Collocational Constructions in English and Spanish: A Usage-based Approach”. Fournal of Social Sciences (2015): 1-13.

Corpas Pastor, Gloria. "Collocations in e-bilingual dictionaries: from underlying theoretical assumptions to practical lexicography and transla- 
tion issues". Collocations and other lexical combinations in Spanish. Theoretical and applied approaches. Eds. Sergi Torner y Elisenda Bernal. London: Routledge. 2017. 173-99.

Coseriu, Eugenio. "Las solidaridades léxicas". Principios de semántica estructural. 2. ${ }^{a}$ ed. Madrid: Gredos, 1981a. 143-61.

Coseriu, Eugenio. "Las estructuras lexemáticas". Principios de semántica estruc-

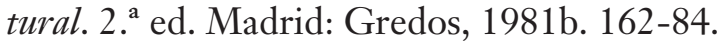

Daneš, František. "The relation of centre and periphery as a language universal". Travaux Linguistiques de Prague 2 (1966): 9-21.

Demonte, Violeta. "Qué es sintáctico y qué es léxico en la interfaz entre sintaxis y léxico-semántica: hipótesis y conjeturas”. Signo \& Seña 15 (2006): 17-41.

Díaz Hormigo, $M^{a}$ Tadea. Disciplinas linguiísticas y formación de palabras. Cádiz: Universidad de Cádiz, 2000.

Dik, Simon C. Gramática funcional. Traducción, glosario de términos técnicos e introducción a la edición española por Fernando Serrano Valverde y Leocadio Martín Mingorance. Madrid: SGEL, 1981.

Ernout, Alfred y Antoine Meillet. Dictionnaire étymologique de la langue latine. Histoire des mots. 4. ${ }^{a}$ ed., 3. ${ }^{a}$ reimp. Paris: Klincksieck, 1979.

García-Page, Mario. "Sobre implicaciones lingüísticas. Solidaridad léxica y expresión fija”. Estudios Humanísticos. Filología 12 (1990): 215-27.

García-Page, Mario. "Adverbios restringidos y adverbios colocacionales”. Revista de Lexicografía VIII (2001-2002): 103-47.

García-Page, Mario. "Colocaciones simples y complejas: diferencias estructurales”. Fraseología contrastiva con ejemplos tomados del alemán, español, francés e italiano. Eds. Ramón Almela, Estanislao Ramón Trives y Gerd Wotjak. Murcia: Universidad de Murcia, 2005. 145-67.

Geckeler, Horst. "Sobre la más moderna y reciente semántica: análisis del contenido en rasgos distintivos". Semántica estructural y teoría del campo léxico. 1. ${ }^{\mathrm{a}}$ ed., 1. ${ }^{\mathrm{a}}$ reimp. Madrid: Gredos, 1984a. 246-81.

Geckeler, Horst. "Descripción o análisis del campo léxico". Semántica estructural y teoría del campo léxico. 1. ${ }^{\mathrm{a}}$ ed., 1. ${ }^{\mathrm{a}}$ reimp. Madrid: Gredos, 1984b. 282-303. Ginebra, Jordi. "Las unidades del tipo dinero negro y dormir como un tronco: ¿naturaleza léxica o gramatical?”. Léxico y gramática. Eds. Alexandre Veiga, Miguel González Pereira y Montserrat Souto Gómez. Lugo: Tris Tram, 2002. 147-54.

Glare, P. G. W. Oxford Latin Dictionary. Vol. V. Oxford: Oxford University Press, 1976. 
González García, Luis. "La noción de manera”. En torno al adverbio español y los circunstantes. Ed. Gerd Wotjak. Tübingen: Gunter Narr, 1996. 11525.

Hausmann, Franz Josef. "O diccionario de colocacións. Criterios de organización". Actas do I Coloquio Galego de Fraseoloxía. (Centro Ramón Piñeiro, Santiago de Compostela, 1997). Coord. Xesús Ferro Ruibal. Vigo: Xunta de Galicia, 1998. 63-81.

Hummel, Martin. "The semiotic basis of conceptual and procedural meaning”. Semántica latina y románica. Unidades de significado conceptual y procedimental. Eds. Benjamín García-Hernández y Azucena Penas Ibáñez. Bern / Frankfurt am Main: Peter Lang, 2016. 57-100.

Ibarretxe-Antuñano, Iraide. "Lexicografía y Lingüística cognitiva". Revista Española de Lingüística Aplicada 23 (2010): 195-213.

Jiménez Calvente, Teresa. "Infiernos de amor o el trágico destino de los enamorados". II Encuentro Internacional de Mitología de la UAH. Espacios Infernales: brujas, demonios y otros personajes literarios del Más Allá (8 al 10 de abril de 2014). Universidad de Alcalá.

Koike, Kazumi. Colocaciones léxicas en el español actual: estudio formal y léxico-semántico. Alcalá de Henares: Universidad de Alcalá/Takushoku University, 2001.

Koike, Kazumi. "Colocaciones complejas en el español actual”. Fraseología contrastiva con ejemplos tomados del alemán, español, francés e italiano. Eds. Ramón Almela, Estanislao Ramón Trives y Gerd Wotjak. Murcia: Universidad de Murcia, 2005. 169-84.

Maldonado, Ricardo. "Claro: de objeto perceptible a refuerzo pragmático". Adjetivos en discurso. Emociones, certezas, posibilidades y evidencias. Ed. María-José Rodríguez-Espiñeira. Santiago de Compostela: Servizo de $\mathrm{Pu}-$ blicacións e Intercambio Científico, 2010. 61-107.

Mendikoetxea, Amaya. "En busca de los primitivos léxicos y su realización sintáctica: del léxico a la sintaxis y viceversa”. Lingüiśtica teòrica: anàlisi i perspectives. Vol. II. Ed. Teresa Cabré Monné. Bellaterra: Universitat Autònoma de Barcelona, Servei de Publicacions, 2007. 55-102.

Moliner, María. Diccionario de uso del español. H - Z. reimp. Madrid: Gredos, 1990.

Muñiz Álvarez, Eva María. "Notas para unha análise comparativa das nocións de restricción léxica colocación”. Cadernos de Fraseoloxía Galega 7 (2005): 177-90.

Muñoz Núñez, $M^{a}$ Dolores. "Colocaciones y restricciones léxicas: criterios 
de diferenciación". Estudios de linguiistica hispánica. Cádiz: Universidad de Cádiz, 2007. 177-98.

Penadés Martínez, Inmaculada. Esquemas sintáctico-semánticos de los verbos atributivos del español. Alcalá de Henares: Universidad de Alcalá, 1994.

Penadés Martínez, Inmaculada. "El modelo de descripción de la oración del lingüista praguense F. Daneš. Su incidencia en la lingüística española". Verba. Anuario Galego de Filoloxía 26 (1999): 247-72.

Penadés Martínez, Inmaculada. "La teoría cognitiva de la metonimia a la luz de locuciones nominales somáticas". Revista Española de Lingiuística 40/2 (2011): 75-94.

Penadés Martínez, Inmaculada. Gramática y semántica de las locuciones. Alcalá de Henares: Servicio de Publicaciones de la Universidad de Alcalá, 2012.

Penadés Martínez, Inmaculada. "Fixación estrutural e desautomatización das locucións”. Cadernos de Fraseoloxía Galega 16 (2014): 273-301.

Penadés Martínez, Inmaculada. "Las colocaciones del tipo verbo más locución adverbial: implicaciones teóricas y aplicadas". Linguïstica en la Red XII (2015): 1-13. 31 de diciembre de 2015. <http://www.linred.es>.

Penadés Martínez, Inmaculada y $M^{a}$ Tadea Díaz Hormigo. "Hacia la noción lingüística de motivación”. Lenguaje figurado y motivación. Ed. María Álvarez de la Granja. Frankfurt am Main: Peter Lang, 2008. 51-68.

Ramchand, Gillian y Charles Reiss. "Introduction". The Oxford Handbook of Linguistics Interfaces. Eds. Gillian Ramchand y Charles Reiss. Oxford: Oxford University Press, 2007. 1-13.

Real Academia Española. Banco de datos (CREA) [en línea]. Corpus de referencia del español actual. Febrero-junio de 2015. <http://www.rae.es>.

Real Academia Española. Diccionario de la lengua española. 23. ${ }^{a}$ ed. Barcelona: Espasa Libros, 2014.

Saussure, Ferdinad de. Curso de lingüística general. 21. a ed. Buenos Aires: Losada, 1916 [1981].

Seco, Manuel, Olimpia Andrés y Gabino Ramos. Diccionario fraseológico documentado del español actual. Madrid: Aguilar, 2004.

Tesnière, Lucien. Éléments de syntaxe structurale. Paris: Klincksieck, 1959.

Thieleman, Werner. "El adverbio: pragmática - gramática - léxico: campo conflictivo". En torno al adverbio español y los circunstantes. Ed. Gerd Wotjak. Tübingen: Gunter Narr, 1996. 59-91.

Trnka, Bohumil y otros. "Prague Structural Linguistics". A Prague School 
Reader in Linguistics. 3. a ed. Comp. Josef Vachek. Bloomington/London: Indiana University Press, 1967. 468-80.

Val Álvaro, José Francisco. "La encrucijada del léxico y la sintaxis". La gramática del sentido: Léxico y Sintaxis en la encrucijada. Eds. José Francisco Val Álvaro y María del Carmen Horno Chéliz. Zaragoza: Prensas Universitarias de Zaragoza, 2010. 17-47.

Valenzuela, Javier, Iraide Ibarretxe-Antuñano y Joseph Hilferty. "La semántica cognitiva". Lingiuística cognitiva. Dirs. Iraide Ibarretxe-Antuñano y Javier Valenzuela. Barcelona: Anthropos, 2012. 41-96.

Veiga, Alexandre, González Pereira, Miguel y Montserrat Souto Gómez, eds. Léxico y gramática. Lugo: Tris Tram, 2002.

Wotjak, Gerd. “Gramática y léxico - ¿gramática en el léxico?”. Léxico y gramática. Eds. Alexandre Veiga, Miguel González Pereira y Montserrat Souto Gómez. Lugo: Tris Tram, 2002. 341-72.

Walker, Crayton. "Factors which influence the process of collocation". Cognitive Linguistic Approaches to Teaching Vocabulary and Phraseology. Eds. Frank Boers y Seth Lindstromberg. Berlin: Mouton de Gruyter, 2008. 291-308.

Zuluaga, Alberto. "Los "enlaces frecuentes" de María Moliner. Observaciones sobre las llamadas colocaciones". Lingiuística Española Actual XXIV/1 (2002): 97-114. 